\title{
DESCAMANDO O NU: O SENTIDO DO DESPIDO NA ARTE CONTEMPORÂNEA
}

\author{
Pelando el desnudo: el sentido del desvestido en el arte contemporanea \\ Peeling the nude: the sense of naked in contemporary art
}

Júlia Mello, Claúdia Oliveira

\begin{abstract}
Resumo
Este artigo apresenta uma análise da construção do corpo nu como categoria estética na cultura ocidental e da subversão da sua associação com o belo, proporcional e harmônico feita através da valorização do corpo "cru" e despido da arte contemporânea. O estudo de Kenneth Clark (1956) tem grande relevância para a manutenção da concepção do nu como elemento central da arte europeia, da idealização do maior grau de sofisticação da arte. Algo totalmente diferente do despido que, segundo o autor, implica em constrangimento e vulnerabilidade. A partir de elementos da metodologia visual crítica e da sua articulação com o feminismo, exploramos o significado de "nu"e "despido"considerando autores como John Berger (1999), Lynda Nead (1992) e Frances Borzello (2012). Os resultados revelam que o nu descamado, o corpo despido e "obsceno" no cenário da arte contemporânea, mostra-se como um importante objeto de práticas culturais que questionam convenções pré-estabelecidas.
\end{abstract}

Palavras-chave: Arte; nu; despido; corpo; gênero.

\section{Resumen}

Este artículo presenta un análisis de la construcción del cuerpo desnudo como categoría estética en la cultura occidental y de la subversión de su asociación con lo bello, proporcional y armónico hecho a través de la valorización del cuerpo "crudo" y"desvestido"del arte contemporáneo. El estudio de Kenneth Clark (1956) tiene gran relevancia para el mantenimiento de la concepción del desnudo como elemento central del arte europeo, de la idealización del mayor grado de sofisticación del arte. Algo totalmente diferente del "desvestido" que, según el autor, implica en constreñimiento y vulnerabilidad. A partir de elementos de la metodología visual crítica y de su articulación con el feminismo, exploramos el significado de "desnudo" y"desvestido" considerando autores como John Berger (1999), Lynda Nead (1992) y Frances Borzello (2012). Los resultados revelan que el desnudo pelado, el cuerpo desvestido y "obsceno" en el escenario del arte contemporáneo, se muestra como un importante objeto de prácticas culturales que cuestionan convenciones preestablecidas.

Palabras clave: Arte; desnudo; desvestido; el cuerpo; género.

\begin{abstract}
This article presents an analysis of the construction of the nude as an aesthetic category in western culture and of the subversion of its association with the beautiful, proportional and harmonic made through the valorization of the "raw" and naked contemporary art's body. The study of Kenneth Clark (1956) has great relevance for the maintenance of the conception of the nude as a central element of European art, of the idealization of the highest degree of sophistication of art. Something totally different from the naked body that, according to the author, implies embarrassment and vulnerability. From the elements of critical visual methodology and its articulation with feminism, we explore the meaning of "nude" and "naked" by authors such as John Berger (1999), Lynda Nead (1992) and Frances Borzello (2012). The results reveal that the peeled nude, the naked and "obscene" body in the contemporary art scene, shows itself as an important object of cultural practices that question pre-established conventions.
\end{abstract}




\section{Introdução}

O nu está condenado a nunca ficar despido. A nudez é uma forma de vestir (BERGER, 1999, p. 54)

A nudez nunca é final: ela abre para uma sucessão indefinida de desnudamentos (NANCY, 2015, p. 19).

[...] desenhar, pintar, modelar os corpos, significava captá-los nus em sua verdade anatômica e, depois, vesti-los como o mandavam as circunstâncias da cena ou da ação (MICHAUD, 2011, p. 541).

As epígrafes acima sugerem que um corpo nu está sempre vestido, possui camadas de convenções artísticas e culturais. Nancy (2015, p. 21) faz a seguinte enumeração: "nu: vencido, triunfante; desfeito, reunido; extraviado, reencontrado; despido, vestido; evidente, indiscernível; despudorado, virtuoso; próximo, longe; sexuado, neutralizado". Afinal, o que é o corpo nu? E o despido?

Comecemos com o clássico estudo de Kenneth Clark (1956). O autor descreve o nu como uma categoria estética, como elemento central da arte europeia, da idealização do maior grau de sofisticação da arte. Algo totalmente diferente do despido. Segundo o autor, o despido implica em constrangimento e vulnerabilidade enquanto o nu carrega o sentido de um corpo em proporção, balanceado e confiante; um corpo "re-formado": "Estar despido é estar desprovido de roupas... A palavra nu por outro lado, no sentido culto não carrega conotação de desconforto" $^{\prime 1}$ (CLARK, 1956, p. 3, tradução nossa). A definição de Clark permite que determinados corpos desprovidos de vestes sejam culturalmente aceitos. O autor indica que o nu se originou no século $\mathrm{V}$ a.C como uma forma de arte e que no século XX, mesmo com a herança grega abalada, sobreviveu. Diferente dessa forma artística que remete ao equilíbrio e à harmonia, para Clark uma massa de corpos despidos traz desilusão e desânimo.

Como sugere John Berger (1999), o nu é sempre uma convenção - e a autoridade para suas convenções deriva de uma certa tradição da arte. Na visão do autor, a definição do nu não pode ser encontrada apenas através das formas artísticas, já que está relacionado também com a sexualidade vivida. Enquanto estar despido significa ser você mesmo, estar nu significa estar investido de objetificação. O corpo se torna um objeto de exibição.

Clark (1956) enfatiza o nu feminino e a sujeição das modelos diante do artista (supostamente homem e heterossexual) que depois de escolher a que lhe agrada está livre para retratá-las consoante as suas noções de beleza, retocando e destacando as melhores características. De acordo com o autor, o corpo despido é apenas o ponto de partida da obra de arte, o nu é a sua construção ideal e é óbvio que lança vestígios de erotismo no espectador. Como indica, a existência do nu feminino se dá através da tentativa de transformar imagens que à primeira vista surgiram em detrimento do desejo físico em "não obscenas". As Vênus, no contexto da arte europeia, seriam o exemplo da transformação da figura da mulher na arte em "celestial", ao invés de "vulgar". Isso comprova o motivo de Apolo, como sugere Frances Borzello (2012, p. 15) ser retratado "desavergonhadamente nu", com pelos púbicos detalhados, enquanto as personificações da Vênus ocultavam sua genitália com as mãos ou através de um pedaço de tecido.

Como Borzello indica, até o Renascimento, o nu feminino tinha pouca relevância ao passo que o masculino podia tomar a forma de Cristo ou de heróis clássicos como herança grega de expressar as qualidades divinas através da perfeição da forma. Mulheres sem roupas tendiam a ser pecadoras como Eva. O contexto religioso contribuía fortemente com a associação da mulher a algo rebaixado, animalesco, em contraponto à espiritualidade e intelectualidade que só o homem seria dotado. "Vênus, deusa do amor, nunca poderia alcançar o mesmo patamar moral de Marte, deus da guerra. Era a nudez masculina que representava o ideal"2 (BORZELLO, 2012, p. 15 , tradução nossa).

A obra que contribuiu para a mudança de sexo do nu ideal, como sugere a autora, é a "Vênus adormecida" (1510, Figura 1), de Giorgione (1478-1510).

\footnotetext{
1 "To be naked is to be deprived of our clothes... The word nude, on the other hand, carries, in educated usage, no uncomfortable overtone" (CLARK, 1956, p. 3).

2 "Venus, goddess of love, could never reach as high a moral ground as Mars, god of war. It was male nudity that represented the ideal" (BORZELLO, 2012, p. 15).
} 
Figura 1 - Giorgione, "Vênus adormecida”, 1510. Óleo sobre tela, 108,5 cm x 175 cm. Dresden.

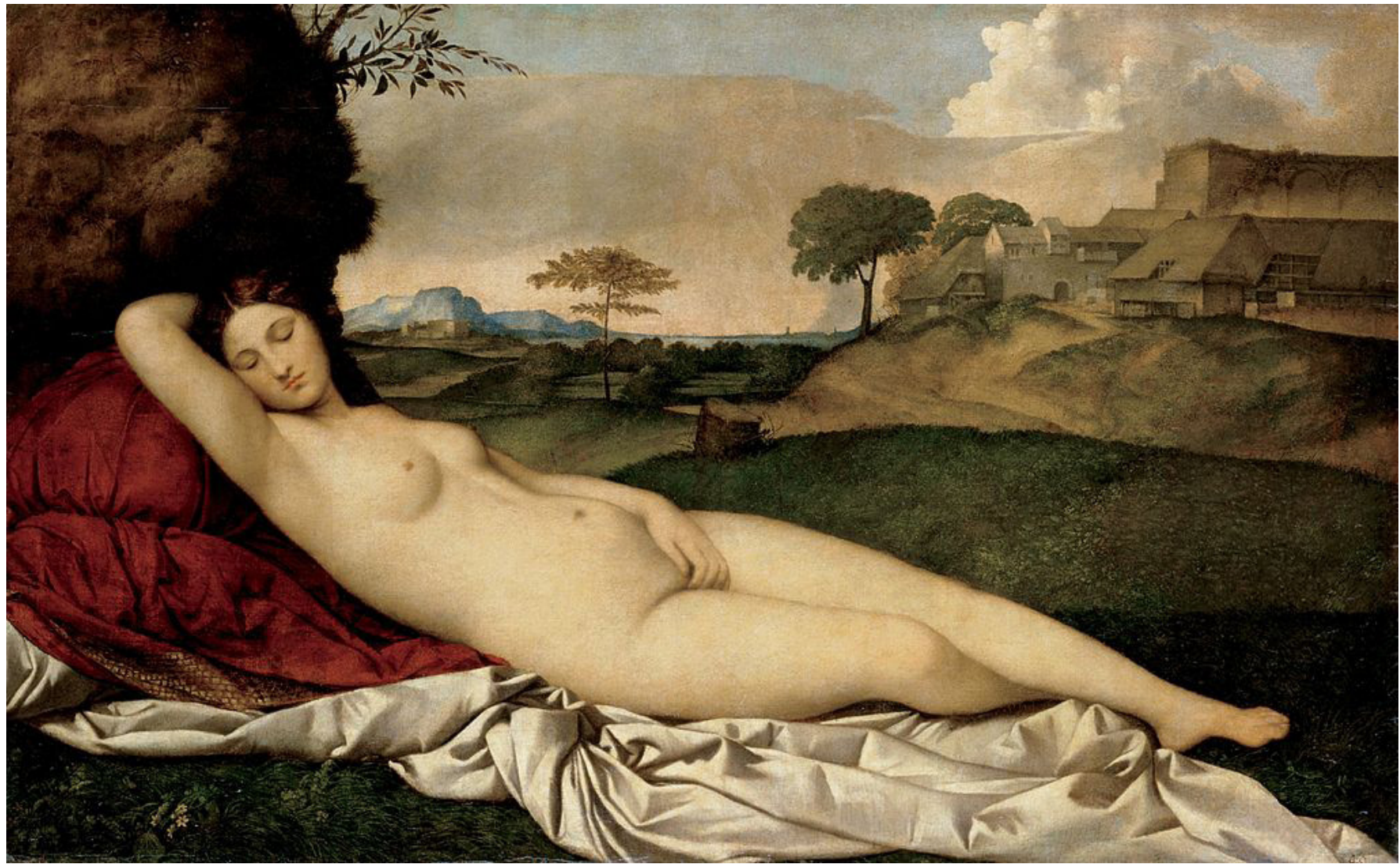

Disponível em: <https://en.wikipedia.org/wiki/Sleeping_Venus_(Giorgione)>. Acesso em: 8 mai. 2018.

Giorgione abriu espaço para a idealização do corpo feminino e da popularização da sua vulnerabilidade diante do olhar. A mulher deitada, visão bela e passiva da perfeição, sugestivamente com a sexualidade camuflada pelas mãos e os seios exibidos, era o mais novo objeto da arte e permearia todo o imaginário cultural ocidental até então, como comprova a Figura 2 que traz uma pequena seleção de nus em poses semelhantes ao longo dos séculos.

Figura 2 - Vênus reclinada na arte ocidental (1520-1900).

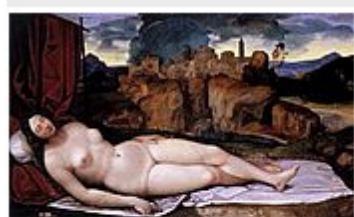

Girolamo da Treviso, 1520

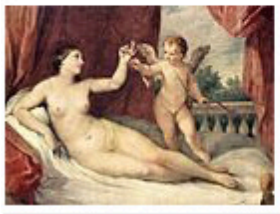

Reni, 1639

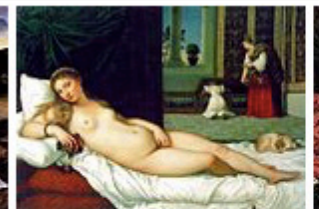

Titian, 1534

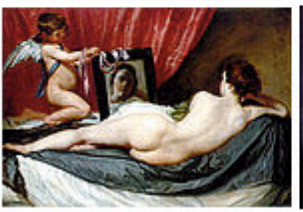

Velázquez, c. 1650

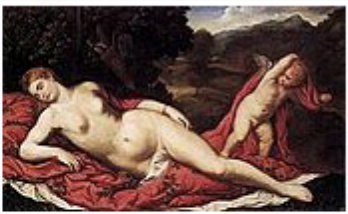

Bordone, 1540

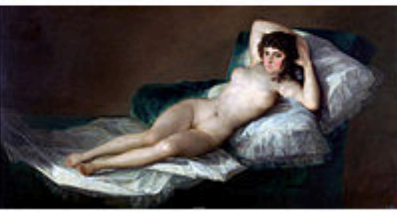

Goya, 1792

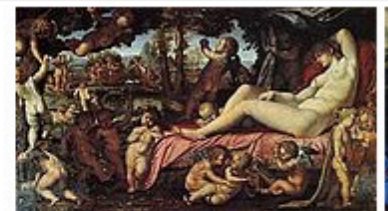

Annibale Carracci, 1602

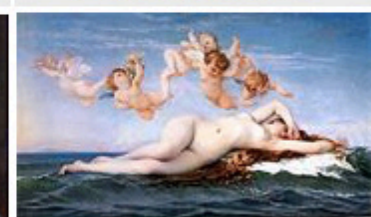

Cabanel, 1863

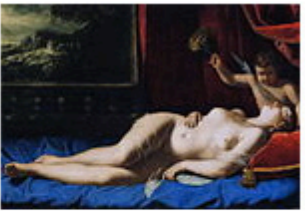

Artemisia Gentileschi, 1625

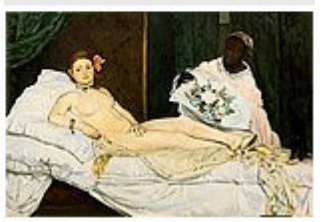

Manet, 1863

Disponível em: < https://en.wikipedia.org/wiki/Sleeping_Venus_(Giorgione)>. Acesso em: 8 de mai. 2018.

De acordo com Berger (1999), na pintura a óleo europeia tradicional, o protagonista nunca é pintado, já que é o próprio espectador, presumidamente homem. Berger aponta que tudo na cena se endereça a ele e que é para ele que as figuras 
assumem sua nudez. Para a sexualidade dele e não a da mulher que é desconsiderada diante do monopólio do prazer masculino.

Retornando à Clark (1956), ao se referir à construção ou forma "ideal", o autor afirma a existência de uma beleza ideal argumentando que se criticamos uma figura porque o pescoço é muito longo, os quadris largos ou os seios pequenos, é porque admitimos em termos concreto a existência de um padrão. Segundo ele, a beleza ideal é a memória difusa do tipo físico peculiar grego de 480 e 440 a.C que foi sendo elaborado como padrão de perfeição do Renascimento ao século XX.

Uma comparação que amplia a nossa compreensão sobre a construção do nu e dos padrões corpóreos ao longo da história da arte é a que Clark faz com a arquitetura: "como um prédio, o nu representa o equilíbrio entre o esquema ideal e as necessidades funcionais"3 (CLARK, 1956, p. 20, tradução nossa). É por isso que afirma que "o nu permanece o exemplo mais completo da transmutação da matéria em forma" ${ }^{4}$ (p. 27, tradução nossa). Para Lynda Nead (1992), a aproximação do nu (feminino) com a arquitetura - baseada na geometria e perspectiva -, impõe uma ordem sobre o corpo feminino. A autora exemplifica o argumento com uma breve análise de "Draughtsman drawing a nude" (1538), de Albrecht Dürer (1471-1528), que evidencia a oposição entre cultura masculina e natureza feminina.

Não é preciso nos estendermos tanto para notarmos que o discurso de Clark (1956) de fato não corresponde às produções contemporâneas. Lynda Nochlin (1999) confronta o autor dizendo que na contemporaneidade qualquer nu que não seja clássico, qualquer corpo despido que não seja apolíneo é o corpo de valor na arte. Segundo ela, o nu clássico está morto e o que vive é o corpo "desconjuntado", feio, excessivo, e a transgressão se dá a partir dele. É um corpo que pode chocar, desafiar e alargar as fronteiras entre as noções convencionais de beleza e feiura.

\section{Da transgressão dos corpos}

Borzello (2012) lança uma reflexão sobre o nu e seus desdobramentos (ou, seria confronto?) na arte contemporânea. Ela afirma que a partir da segunda metade do século XX o nu deu lugar ao corpo e que hoje a representação do nu perfeito e do corpo magro é propriedade dos fotógrafos publicitários que aprimoram as formas, apagam as veias, inflam seios e glúteos. Na arte, já não há mais nus e sim despidos. Corpos descamados de discursos, pudores, moralismos. Corpos que carregam o tom de incômodo e desconforto que Clark (1956) desejava evitar.

Em uma linha ainda mais direcionada para a questão do nu feminino como elemento essencial para a compreensão da construção de valores culturais em tordo do corpo feminino, da representação, do feminismo e de políticas culturais, está o estudo de Nead (1992) que tenta criar uma potência diante do "despido", relacionando-o ao obsceno. Como indica, mais do que qualquer tema ou assunto, o nu feminino conota "Arte". O corpo feminino emoldurado pendurado em um museu ou galeria é "[...] o ícone da cultura ocidental, um símbolo da civilização e

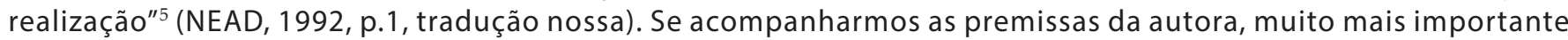
do que esclarecer o que é o nu é elucidar o que é o nu feminino para a história da arte ocidental. A hipótese de Nead é a de que o corpo feminino foi - e tem sido - visto como sem forma, incompleto e os procedimentos e convenções tomados pela "alta" arte para controlar esse corpo desregrado era colocá-lo dentro das fronteiras seguras do discurso estético, contê-lo. A relevância dessa conjectura está na conclusão de que o nu feminino propõe definições particulares sobre o corpo feminino, isto é, nem todo corpo feminino pode ser transformado em nu. Além disso, essa categoria exige modos de visualização e espectadores específicos. Visualização pautada na contemplação, nas alegações da estética onde as obras de arte funcionavam para reforçar a unidade e integridade do observador (mais uma vez, supostamente homem, branco e heterossexual) e obedeciam a ordem da perfeição. O que fugisse disso estaria longe de ser considerado arte e poderia ser aproximado com certa frequência do obsceno. O corpo obsceno, como define Nead, é aquele sem bordas, que não se contém e obscenidade é o que move e desperta o espectador, ao invés de provocar quietude e noção de completude.

Sob a ótica de Nead, a fotografia de Robert Mapplethorpe, "Lisa Lyon" (1980, Figura 3) é um bom exemplo de uma imagem que traz os elementos elencados por Clark (1956) como "ordem", "precisão" e "lógica" já que tanto a modelo, quanto o fotógrafo colaboram com o ordenamento do corpo feminino. Ambos parecem escultores clássicos na busca da estética ideal, transformando o material "cru", bruto, em arte.

3 "Like a building, the nude represents a balance between an ideal scheme and functional necessities" (CLARK, 1956, p. 20).

4 "The nude remains the most complete example of the transmutation of matter into form" (Ibid. p. 27).

5 "[...] It's an icon of Western culture, a symbol of civilization and accomplishment" (NEAD, 1992, p. 1). 
Figura 3 - Robert Mapplethorpe, Lysa Lyon, 1980. Fotografia.

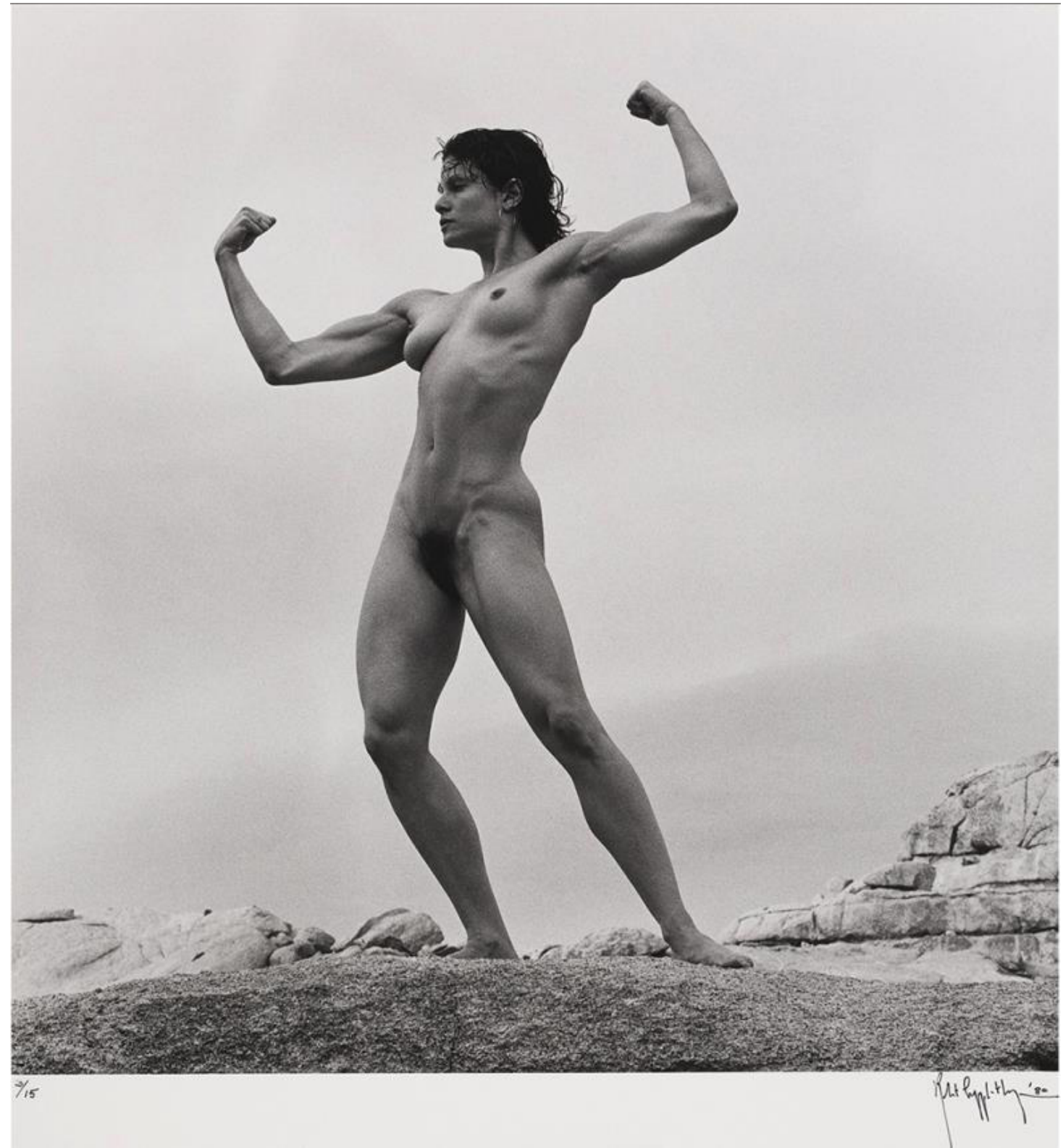

Disponível em: <http://www1.folha.uol.com.br/ilustrissima/2016/04/1763754-retratos-do-underground-em-la.shtml>.

Acesso em: 31 mar. 2017.

Evidentemente Nead (1992) não desconsidera o valor que a obra possui, sobretudo na desconstrução de determinados padrões femininos (Lyon é bodybuilder), mas reforça que nesse trabalho a modelo foi emoldurada, tendo o seu corpo aparentemente atingido o mais alto grau da forma contida.

Em 1960, corpos femininos contidos também haviam sido apresentados em Paris por Yves Klein (1928-1962). O artista pintou modelos com a cor que ficaria conhecida como "International Klein Blue", as fez se "carimbarem" em grandes folhas como se fossem pincéis vivos e o resultado foi apresentado com o título de "Antropometrias". A ação foi realizada com uma orquestra que tocava a "Sinfonia Monótona" composta pelo artista que consistia em apenas uma nota tocada por 20 minutos seguida de 20 minutos de pausa enquanto uma plateia assistia (YVES, 2018). No vídeo ${ }^{6}$ fica ainda mais clara a sujeição das modelos aos olhares masculinos que predominavam na sala e a imposição do artista como proprietário dos "objetos".

Descte mreactos do século XX, o corpo despido toma sentido no confronto de discursos opressores e reguladores da sexualidade e das diferenças. Como indica Borzello (2012), Berger na década de 1970 pareceu desconsiderar a forte atuação do feminismo na arte e o papel crescente das mulheres desde o século XIX na desconstrução do "olhar" masculino e em um novo modo

6 Disponível em: <https://www.youtube.com/watch?reload=9\&v=kjOBQD1oOG0>. Acesso em: 9 mai. 2018. 
de representar o corpo feminino, muitas vezes, tomando o obsceno e o erótico como base. Segundo Carolee Schneemann (1991, p. 28, tradução nossa),

artistas mulheres exploram imagens eróticas porque nossos corpos exemplificam um campo de batalha histórico estamos desmantelando a ideologia sexual convencional e sua punição de supressões - e porque nossa experiência com nossos corpos não correspondeu a representações culturais ${ }^{7}$.

Em 1963, a provocação de Schneemann com as convenções artísticas incluía "descamar" o nu até revelar seu clitóris (Figura 4), o que resultou em reações diversas por parte da crítica, desde a associação com rituais xamânicos até a pornografia. A trajetória artística de Schneemann é permeada por censuras o que a faz lançar a questão sobre o que de fato torna as suas obras obscenas. Porque usa o corpo sem artifício, "fetichização" ou porque ela controla a sua corporeidade e representação?

Figura 4 - Carolee Schneemann, "Eye body 5", 1963. Papel de gelatin e prata, 29,8 cm x 24,1 cm.

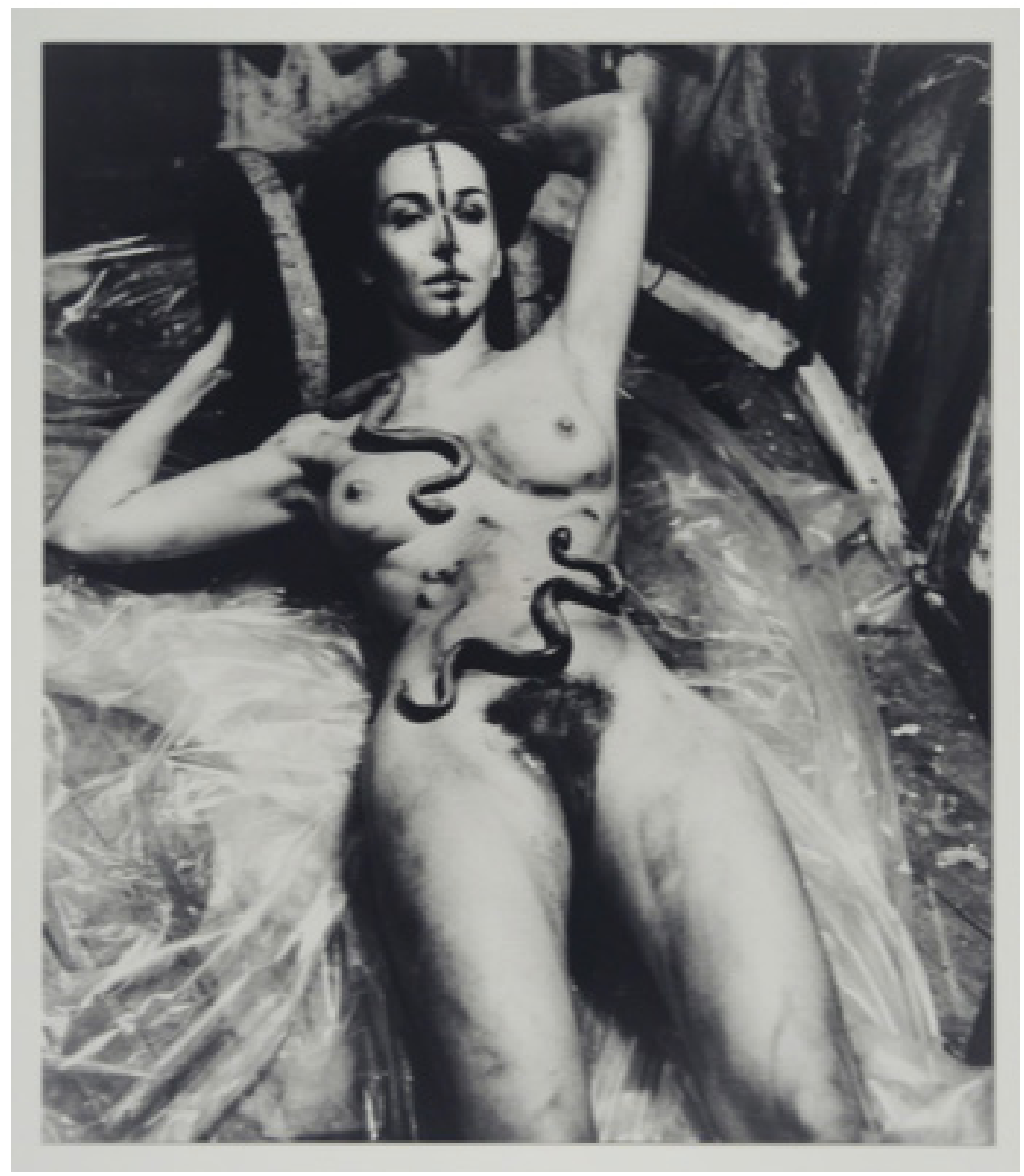

Disponível em: < https://www.artsy.net/artwork/carolee-schneemann-eye-body-5>. Acesso em: 9 mai. 2018.

Em 1974 a desigualdade entre artistas homens e mulheres no campo do minimalismo era protestada por Lynda Ben-

7 "Women artists explore erotic imagery because our bodies exemplify a historic battleground - we are dismantling conventional sexual ideology and its punishing suppressions- and because our experience of our bodies has not corresponded to cultural depiction" (SCHNEEMANN, 1991, p. 28). 
glis (1941-) na Artforum ao mesmo tempo em que divulgava sua próxima exposição que incluía a obra "Smile" (1974). A artista que na época tinha 32 anos, aparece despida e bronzeada segurando um pênis de látex entre as coxas de maneira desafiadora (Figura 5).

Figura 5 - Lynda Benglis, Artforum, nov. 1974.

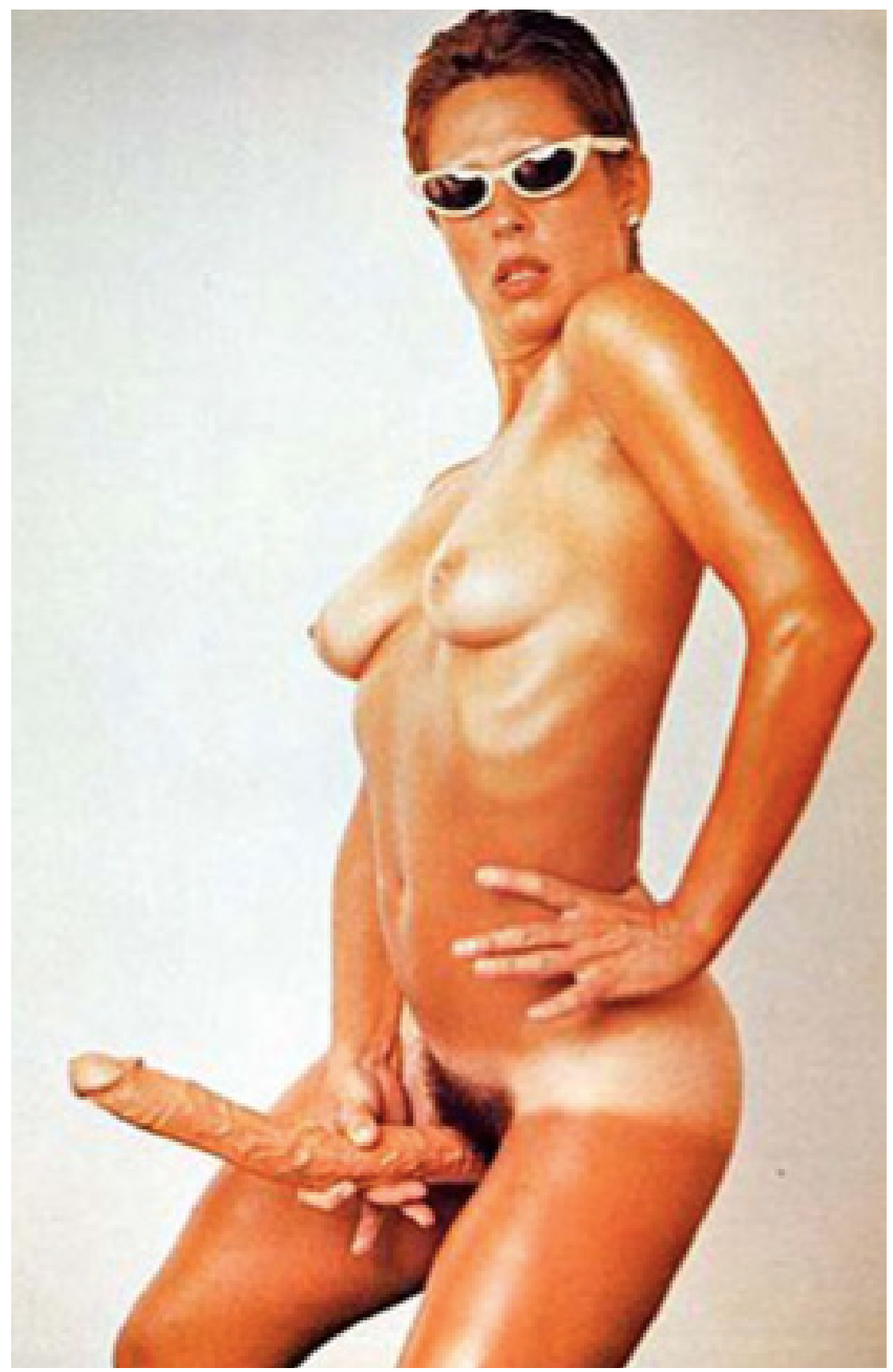

Disponível em: <https://www.widewalls.ch/campy-art-definition-artworks-culture/>. Acesso em: 9 mai. 2018.

De acordo com Roberta Smith (2009), diversas artistas aprovaram entusiasticamente a fotografia de Benglis e, concomitantemente, visões conflitantes em torno do feminismo, da pornografia, da responsabilidade editorial (e crítica) da revista, da economia artística, da construção da reputação e licença artística iam surgindo. Segundo Smith, o falo mais surpreendente da obra talvez seja o metafórico que resulta da perfeição afinada: o senso de poder, direito, agressividade e franqueza tantas vezes entendido como de domínio dos homens.

A obra "Matrix" (1999, Figura 6) de Jenny Saville pode ser aproximada da fotografia de Benglis por também provocar a binaridade de gênero. Saville apresenta a transgênero Del LaGrace Volcano (1957-), que se auto intitula "abolicionista do gênero". 
Figura 6 - Jenny Saville, "Matrix", 1989. Óleo sobre tela, 213,4 cm x 304,8 cm. Gagosian Gallery

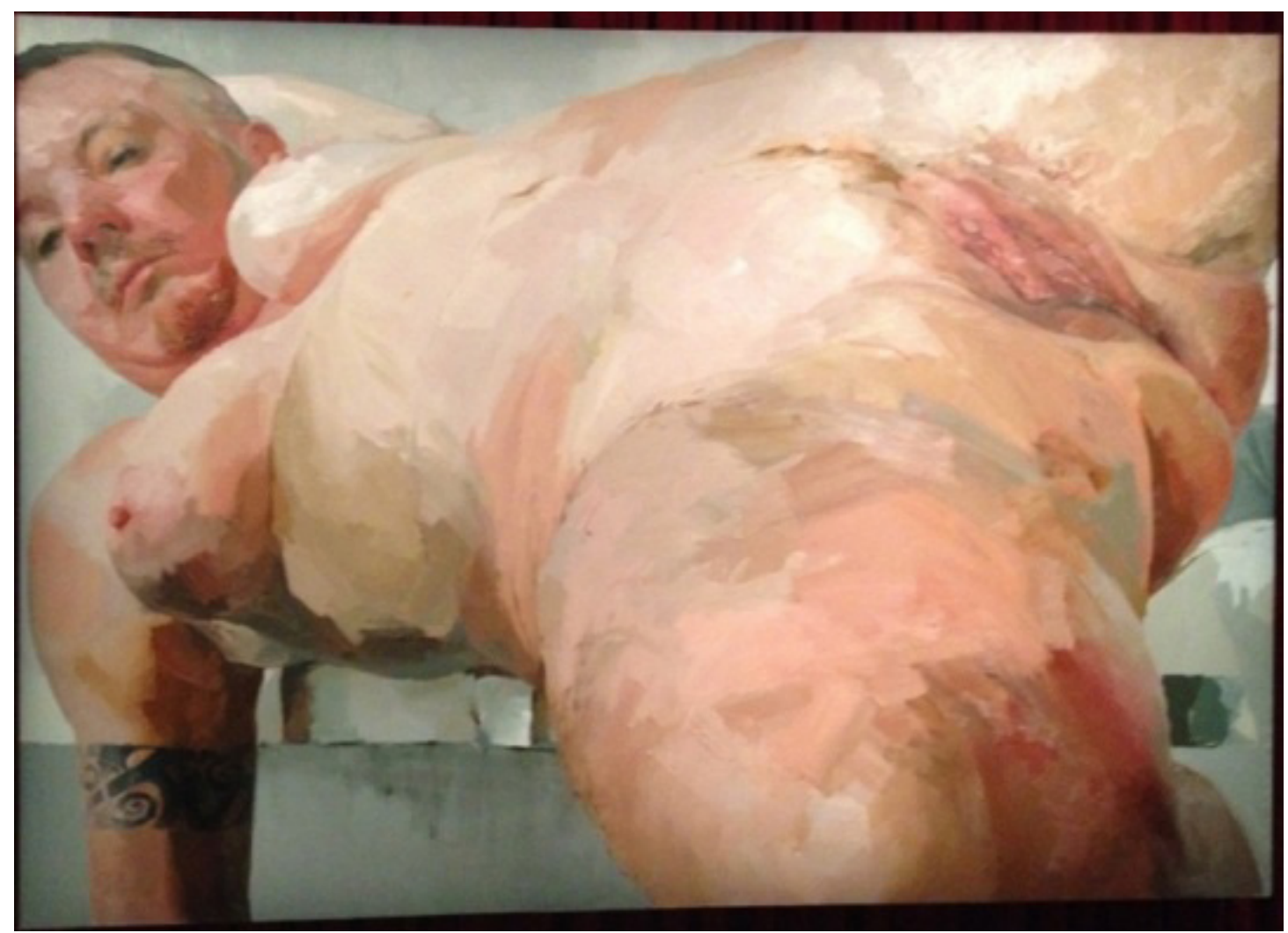

Fonte: artsy.net/artwork/jenny-saville-matrix. Acesso em: 3 jan. 2015

LaGrace viveu 37 anos como mulher e depois, mais engajada na teoria queer, decidiu abandonar qualquer ideia que se relacionasse biologicamente a ser homem ou mulher. Saville faz transparecer em suas obras a questão do grotesco, da imagem perturbadora e até agressiva, mesclada com a sensualidade. "Matrix" mostra um corpo pouco convencional, na pose tão convencional comentada por nós em respeito à tradição da história da arte. Uma paisagem fria, como parecem ser todas as outras construídas pela artista, onde o primeiro plano (da genitália feminina) se confronta com o último plano (do rosto com barba e feições masculinas). Vale lembrar que as dobras e "sobras" de gordura nos corpos representados por Saville também indicam uma forma de protestar contra os cânones vigentes.

\section{3. Últimas análises}

São inúmeras as obras que poderíamos ainda citar em termos de provocações diante da construção do nu ideal no contexto da contemporaneidade. Optamos por encerrar o presente artigo com algumas considerações sobre o trabalho de Laura Aguilar, cuja ênfase no corpo despido reforça o caráter político do projeto da artista.

A série "Clothed/Unclothed" (Vestido/Despido) produzida entre 1990 e 1994 constitui-se em dípticos com imagens feitas por Laura Aguilar, de maneira colaborativa, com seu círculo de amigos e familiares. As pessoas vestidas aparecem à esquerda e as despidas à direita, na maioria das vezes em poses parecidas. A imagem final (da direita), correspondente a uma espécie de "conclusão" dos retratados e segundo Swartz (2010), foi escolhida por eles, entre duas opções fornecidas por Aguilar. Amelia Jones (2016) chama a atenção para seus olhares diretos e indiferentes e para a disposição dos corpos como se fossem uma "fortaleza" (poses of fortitude). O espectador se depara com fotografias em preto e branco feitas em estúdio, com o fundo escuro, que variam em número de participantes e que de certa maneira, desafiam o espectador desconstruindo antigos valores engessados socialmente.

De acordo com Smith e Watson (2012), quando falamos em trabalhos autobiográficos de artistas mulheres na contemporaneidade, falamos em ubiquidade. Isto é, falamos em uma expansão do conceito de autorretrato. Muitas vezes há uma extensão da artista que se direciona a determinado objeto, texto, disseminação vocal (para trabalhos em áudio) ou a impressões de subjetividades (imprints of subjectivity). No caso de Aguilar, há inclusive uma intenção de autorrepresentação a partir de outras pessoas - que como veremos a seguir, se identificam com a artista seja por questões de opção sexual, 
seja pela rejeição da binaridade de gênero.

Em "Cheri and Sue" (1994, Figura 7) confirmamos a desconstrução dos valores socioculturais enraizados ao observar a participação do casal formado pelas duas artistas Cheri Gauke (1954-) e Sue Maberry que extrapolam as fronteiras da família tradicional norte-americana, sobretudo se levarmos em consideração o contexto histórico das fotografias. De acordo com Swartz (2010), elas foram tiradas três semanas antes do nascimento das gêmeas do casal e se encontram penduradas em cima da cama das artistas, em um ângulo que pode ser visto da cozinha, o que reforça a intencionalidade em reafirmarem suas identidades.

No lado direito do díptico, as duas artistas estão sem roupa, Sue abraça Cheri em pose que enfatiza ainda mais a gravidez da parceira. Contrastando por exemplo com "a melhor pintura" de nu segundo o The Times, a "Vênus ao espelho" (1647) de Velázquez (1599-1660), caracterizada pela sua naturalidade e pureza, o corpo à mostra de Cheri e Sue seria um exemplo do despido e obsceno, o corpo que foge das contenções heteronormativas, que não traz a tradicional "pureza", nem respeita a moral, tampouco é "proporcional" na escala clássica. Dessa forma, Aguilar faz um jogo de construção de identidades e de desconstrução do olhar do espectador, que passa a ter "acesso" a diferentes realidades que são muitas vezes invisíveis na sociedade.

Figura 7 - Laura Aguilar, "Cheri and Sue" da série "Clothed/Unclothed", 1994. Papel de gelatina e prata, 40,64 cm x 50,80 cm, Reprodução da coleção de Cheri Gauke e Sue Maberry, Los Angeles, CA.

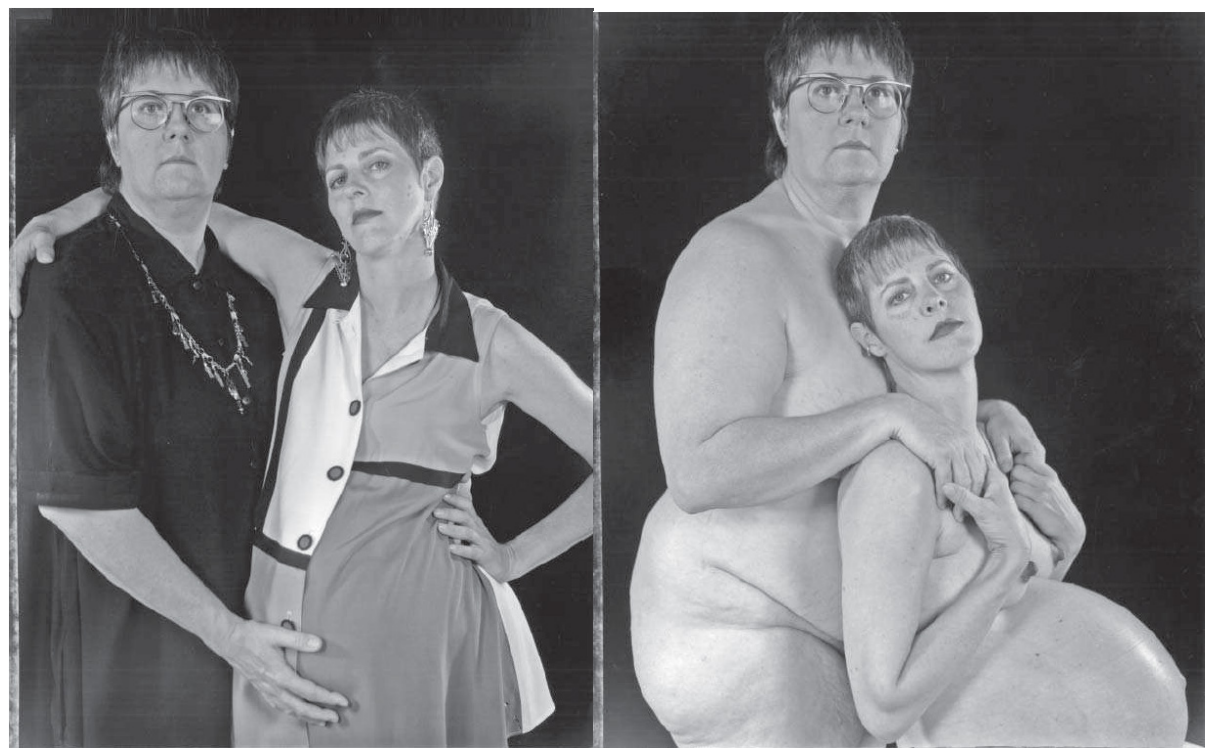

Disponível em: <https://www.researchgate.net >. Acesso em: 10 fev. 2017.

Aguilar indica que o espectador é tão vulnerável quanto as pessoas retratadas em toda a série, porque à medida que veem os corpos despidos, esperam ver a si mesmos (JONES, 2016).

O nu descamado, o corpo despido e obsceno no cenário da arte contemporânea, mostra-se como um importante elemento de práticas culturais que questionam convenções pré-estabelecidas. São corpos que estremecem os códigos de conduta e moral da sociedade ocidental. Corpos que confrontam as barreiras da exclusão.

\section{Referências}

BERGER, John. Modos de ver. Rio de Janeiro: Rocco, 1999.

BORZELLO, Frances. The naked nude. 1 ed. Londres: Thames \& Hudson, 2012.

CLARK, Kenneth. The nude: a study in ideal form. 1 ed. Nova Jersey: Princeton University Press, 1956.

JONES, Amelia. Clothed/Unclothed: Laura Aguilar's Radical Vulnerability. 2016. Catálogo da exposição Laura Aguilar: show and tell. Vincent Price Art Museum. 33 p. 
MICHAUD, Yves. Visualizações - o corpo e as artes visuais. In: CORBIN et. al. História do corpo: as mutações do olhar. $\mathrm{O}$ século XX. 4 ed. Petrópolis: Vozes, 2011. p. 541-566.

NANCY, Jean-Luc. Corpo, fora. 1 ed. Rio de Janeiro: 7letras, 2015.

NEAD, Lynda. The female nude: art, obscenity and sexuality. 1 ed. Londres: Routlege, 1992.

NOCHLIN, Linda. Offbeat and Naked. Artnet.com, nov. 1999. Disponível em: <http://www.artnet.com/Magazine/ FEATURES/nochlin/nochlin11-5- 99.asp>. Acesso em: 21 jun. 2018.

SCHNEEMANN, Carolee. The obscene body/politic. Art Journal, v. 50, n. 4, Censorship Il, p. 28-35. Nova York: College Art Association, 1991.

SMITH, Roberta. Art or ad or what? It caused a lot of fuss. In: The New York Times, 24 jul. 2009. Disponível em: <https://www. nytimes.com/2009/07/25/arts/design/25benglis.html>. Acesso em: 24 jun. 2018.

SMITH, Sidonie; WATSON, Julia. Interfaces: women, autobiography, image, performance. 5 ed. Michigan: University of Michigan Press, 2012.

SWARTZ, Anne. The Home that the Woman's Building Built: Cheri Gaulke and Sue Maberry Construct a Visual Narrative of the Lesbian Family. In: Journal of Lesbian Studies, abr. 2010. Disponível em: <https://www.researchgate.net/figure/43227892 fig3_FIGURE-2-Laura-Aguilar-Cheri-and-Sue-1994-1994-from-Clothed-Unclothed-series-gelatin>. Acesso em: 17 fev. 2017.

YVES Klein. MoMa. Disponível em: <https://www.moma.org/collection/works/80530>. Acesso em: 24 jun. 2018. 